\title{
Clinical profile of viper envenomations in Kerala, India: some unanswered questions
}

This article was published in the following Dove Press journal: International Journal of General Medicine

\author{
Maya Gopalakrishnan' \\ Suman Saurabh ${ }^{2}$ \\ Tarun Kumar Dutta ${ }^{3}$ \\ 'Department of Internal Medicine, \\ Pondicherry Institute of Medical \\ Sciences, Puducherry, India; \\ ${ }^{2}$ Neglected Tropical Diseases- \\ WHO India, Muzaffarpur, India; \\ ${ }^{3}$ Department of Internal Medicine, \\ Mahatma Gandhi Medical College and \\ Research Institute, Puducherry, India
}

Correspondence: Maya Gopalakrishnan Department of Internal Medicine,

Pondicherry Institute of Medical Sciences,

Puducherry 605014, India

Tel +9l 9994492075

Email maya.gopalakrishnan@gmail.com

\section{Dear editor}

We congratulate Kumar et al for their relevant study "Clinical and epidemiologic profile and predictors of outcome of poisonous snake bites - an analysis of 1,500 cases from a tertiary care center in Malabar, North Kerala, India" published in June 2018 in the International Journal of General Medicine. ${ }^{1}$ The study is noteworthy in being one of the largest series addressing snake bites from the subcontinent. The study has succeeded in highlighting several important findings related to snake envenomation, which is a serious and neglected problem in India and other tropical countries.

An important finding that has surfaced from this study is the emergence of humpnosed pit viper (Hypnale hypnae) - accounting for nearly $25 \%$ of envenomations. This is a cause for serious concern as the widely used Indian polyvalent antivenom does not neutralize Hypnale venom. ${ }^{2}$ Thus, there is an urgent need to reassess and address the adequacy of the Indian polyvalent antivenom in light of these findings.

Other interesting findings reported are pituitary apoplexy and acute angle closure glaucoma, which have been encountered in Russell's viper envenomation patients from Southern India. ${ }^{3,4}$ However, it is surprising that none of the patients with Russell's viper envenomation exhibited neurotoxic symptoms. This finding is usually associated with venom induced capillary leak syndrome. Neurologic manifestations have also been reported to occur in over $50 \%$ of Russell's viper envenomation patients from Srilanka. ${ }^{5}$ It is unclear whether this difference is as a result of regional intraspecific variations in the Russell's viper venom or if the authors have not reported the number of patients who had both hemotoxic and neurotoxic manifestations.

From our clinical experience, we agree that patients with features of increased capillary permeability often have poor outcomes. In this regard, it would also be useful to know how many patients with features of increased capillary permeability developed early refractory hypotension and how many succumbed to other causes in the late phase.

We note that the mean antivenom use in viper envenomation is 18.5 vials with a maximum of 20 vials. This suggests that most patients required higher doses of antivenom. It would be of use to know the transfusion requirements of patients, especially those with hump-nosed pit viper envenomation.

We suggest that the authors consider adjusting the risk factors for mortality by using a multivariable logistic regression model that will help to identify independent predictors.

This will prove useful for clinicians involved in the management of snake bite victims. 


\section{Disclosure}

The authors report no conflicts of interest in this communication.

\section{References}

1. Kumar KS, Narayanan S, Udayabhaskaran V, Thulaseedharan NK. Clinical and epidemiologic profile and predictors of outcome of poisonous snake bites - an analysis of 1,500 cases from a tertiary care center in Malabar, North Kerala, India. Int J Gen Med. 2018;11: 209-216.
2. World Health Organization. Guidelines for the management of snakebites, 2nd ed. WHO Regional Office for South-East Asia. Available from: http://www.who.int/snakebites/resources/9789290225300/en/. Accessed September 02, 2018.

3. Srinivasan R, Kaliaperumal S, Dutta TK. Bilateral angle closure glaucoma following snake bite. J Assoc Physicians India. 2005;53:46-48.

4. Rajagopala S, Thabah MM, Ariga KK, Gopalakrishnan M. Acute hypopituitarism complicating Russell's viper envenomation: case series and systematic review. QJM. 2015;108(9):719-728.

5. Silva A, Maduwage K, Sedgwick M, et al. Neurotoxicity in Russell's viper (Daboia russelii) envenoming in Sri Lanka: a clinical and neurophysiological study. Clin Toxicol. 2016;54(5):411-419.

Dove Medical Press encourages responsible, free and frank academic debate. The content of the International Journal of General Medicine 'letters to the editor' section does not necessarily represent the views of Dove Medical Press, its officers, agents, employees, related entities or the International Journal of General Medicine editors. While all reasonable steps have been taken to confirm the content of each letter, Dove Medical Press accepts no liability in respect of the content of any letter, nor is it responsible for the content and accuracy of any letter to the editor.

\section{Publish your work in this journal}

The International Journal of General Medicine is an international, peer-reviewed open-access journal that focuses on general and internal medicine, pathogenesis, epidemiology, diagnosis, monitoring and treatment protocols. The journal is characterized by the rapid reporting of reviews, original research and clinical studies across all disease areas.
The manuscript management system is completely online and includes a very quick and fair peer-review system, which is all easy to use. Visit http://www.dovepress.com/testimonials.php to read real quotes from published authors.

Submit your manuscript here: https://www.dovepress.com/international-journal-of-general-medicine-journal 